\title{
Extremity Injuries Remain A High Surgical Workload In A Conflict Zone: Experiences Of A British Field Hospital In Iraq, 2003
}

T Ramalingam

ABSTRACT
Background
Duringthis conflict 34 Field Hospital, the
sole Coalition field hospital located in
Iraq, received and treated casualties with
a wide range of injuries. Located very
closeto the front line during the period of
combat hostilities, it was potentially
going to deal with relatively fewer battle-
injured extremities.
Method

A retrospective review of battle casualties admitted to the hospital was carried out based on casualty records and operating theatre logbooks. Data was collected for the period between the 26th March and the 8th May, focusing on casualties who had surgery for battle-injured extremities during the conflict.

Results

Sixty eight (55\%) of the 124 casualties who underwent surgery did so for battle injuries to extremities. $139(58 \%)$ of all operating theatre episodes and 189 (53\%) of all surgical procedures undertaken were for battle-injured extremities. Fourteen major limb amputations were carried out from a total of 87 battleinjured limbs that had surgery, giving an amputation rate of sixteen percent (14/87).

Conclusion

The experience at 34 Field Hospital confirms that extremity injuries do confer a high surgical workload in war. Surgical resources should, therefore, be aimed at this and surgical teams deployed to such environments should be well versed in the surgical management of casualties with limb trauma.

\section{Background}

$M$ edical facilities in a conflict zone receive and treat casualties with a wide range of injuries. The workload and type of surgical intervention of field surgical teams is determined by many factors. T hese include the type and intensity of the conflict itself and the efficiency of casualty retrieval from the point of wounding. The role of the medical facility, whether it is for humanitarian purposes or purely to support a strategic military effort, will no doubt also influence the surgical workload.

Treatment of casualties with extremity injuries is common in war. This is supported by the experiences of International Committee of Red Cross (ICRC) hospitals in A sia and in Africa (1). Among the Afghan war wounded treated in the ICRC hospital, Quetta, two thirds of patients were treated for limb injuries and those with long bone fractures needed the greatest number of repeated operations and longest hospitalisation time (2). It has been argued that the distant location of ICRC hospitals from the front line means that 'severely' injured casualties e.g. with abdominal, chest and head wounds, do not survive to make it to these facilities. D oes this mean that field hospitals located near front lines receive or treat fewer extremity-injured casualties?

A recent paper describing the combined surgical experience in ten field hospitals during the I ran-I raq war, lists laparotomy as the commonest surgical procedure performed, comprising $30 \%$ of all surgical interventions (3). The authors quote the subsequent commonest surgical procedures as those to the chest $(21.5 \%)$ with "orthopaedic" procedures, comprising of only $16.8 \%$ of all surgical interventions.

Based on the surgical experience of 34 Field Hospital, the sole Coalition field hospital located very close to the front line, at the time of the conflict, this paper aims to highlight the high surgical workload conferred by battle-injured extremities in a conflict setting.

\section{Method}

At the onset of the war in Iraq, 34 Field Hospital, a 200-bedded British Field H ospital, was mobilised to southern I raq. It was established in its forward position on the 26th $\mathrm{M}$ arch in order to provide medical support for Coalition troops and to deal with Iraqi casualties. The hospital comprised of a reception/triage area, an eight bay resuscitation area, three operating theatres ( 2 operating tables in each), an intensive care unit and 8 wards. There were limited pathology and radiology services available. Six surgeons ( 3 general and 3 orthopaedic) deployed with the hospital and worked as paired specialists.

Data was collected retrospectively from the surgical casualty database, individual casualty records, and from the operative logbooks. From these sources the number of casualties who underwent surgery for both battle and non-battle injuries were determined. The numbers of operative procedures performed and of operating 
theatre episodes were tabulated. A mong the battle-injured casualties, the mechanism of injury (MOI) was also recorded in their notes at the time of admission.

Finally, the number of major limb amputations (proximal to carpals/tarsals) performed was noted and the amputation rate (number of amputations per battleinjured limbs operated on) was determined.

$D$ ata was obtained for the six-week period between the 26th $M$ arch and the 8th M ay.

Table 1. Five commonest $D$ iseases $\mathrm{N}$ on- $\mathrm{B}$ attle I njuries (DNBI.)

\begin{tabular}{|l|c|c|}
\hline Condition & Number of Casualties & $\begin{array}{c}\text { Percentage of Total } \\
\text { Surgical Admissions (\%) }\end{array}$ \\
\hline M usculoskeletal & 161 & 37 \\
\hline Burns & 37 & 9 \\
\hline U reteric Colic & 30 & 7 \\
\hline $\begin{array}{l}\text { N on-specific } \\
\text { abdominal pains }\end{array}$ & 27 & 6 \\
\hline H ead injuries & 19 & 4 \\
\hline
\end{tabular}

\section{Results}

During the six-week period there were 432 admissions to surgical beds. Of these, 124 (29\%) casualties underwent surgery of whom $73(59 \%)$ were Iraqi nationals, comprising of both prisoners of war and civilians. Eighty-two of the $124(66 \%)$ casualties underwent surgery for battle injuries. Table 1 lists the five commonest Disease N on-Battle Injuries (D N BI) seen at $34 \mathrm{~F}$ ield hospital. Sixty-eight casualties had surgery for battle-injured limbs, representing $55 \%$ of all casualties who had surgery and $83 \%$ of all casualties that underwent surgery for battle injuries

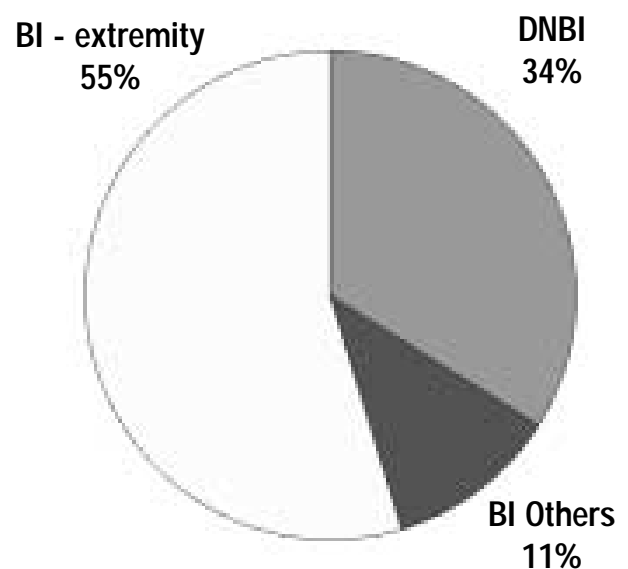

Fig 1. Patients U ndergoing Surgery: Proportions Due to Battle Injury (BI) and D isease N on-Battle Injury (D N BI).

Table 2 lists the most frequent surgical procedures performed in relation to the anatomical site of injury. Examples of how this was determined are illustrated with two of the cases: casualty $A$, who underwent surgery following gunshot wounds. He had a laparotomy, resection of a segment of small bowel and debridement of buttock wounds. We considered casualty $A$ to have had 3 procedures. This approach was used to take into account that we had performed two 'negative' laparotomies. C asualty B, who underwent debridement of fragmentation wounds to both shoulders, would be deemed to have had 2 procedures.

Table 2 shows that $53 \%(n=189)$ of all surgical procedures were performed on battle-injured extremities, the second commonest group of procedures being related to abdominal injuries, $13 \%(n=45)$.

Table 2. N umber of Surgical Procedures.

\begin{tabular}{|l|l|l|}
\hline Procedure & Number & $\begin{array}{l}\text { Percentage of } \\
\text { Total (\%) }\end{array}$ \\
\hline Total & 358 & \\
\hline Battle Injured (B.I) & 303 & 85 \\
\hline Extremity B.I & 189 & 53 \\
\hline Abdomen B.I & 45 & 13 \\
\hline Chest B.I & 21 & 6 \\
\hline
\end{tabular}

Table 3 lists the number of operating theatre patient episodes in relation to the anatomical site of injury. A gain, using the examples casualty $A$ and $B$ given above, the former required only one theatre episode, while casualty $B$, in returning to theatre for delayed primary closure of his wounds, was recorded to have had 2 theatre episodes.

Fifty eight percent $(n=139)$ of all operating theatre patient episodes were for casualties with battle-injured extremities. Casualties with abdominal injuries only constituted $8 \% \quad(n=20)$ of all operating theatre patient episodes. Of these 20 theatre episodes, 14 were for laparotomies two of which were 'negative' laparotomies. Among the casualties operated on for chest injuries, two underwent thoracotomies (Table 3).

Table 3. N umber of O perating T heatre Patient E pisodes.

\begin{tabular}{|l|l|l|}
\hline E pisodes & Number & $\begin{array}{l}\text { Percentage of } \\
\text { Total (\%) }\end{array}$ \\
\hline Total & 238 & \\
\hline Battle Injured (B.I.) & 192 & 81 \\
\hline Extremity B.I. & 139 & 58 \\
\hline Abdomen B.I. & 20 & 8 \\
\hline Chest B.I. & 14 & 6 \\
\hline
\end{tabular}

Figure 2 shows the number and pattern of distribution of extremity injuries according to the mechanism of injury (MOI). Forty percent $(n=35)$ of battleinjured limbs underwent surgery for fragmentation injuries. Injuries to the lower limbs were mainly caused by gunshot wounds $(n=21)$ and fragmentation $(n=20)$ as opposed to blast $(n=6)$.

Fourteen major amputations were performed in 13 patients (Table 4). T here were fewer upper limb $(n=6)$ amputations than lower limb $(n=8)$ ones. The overall rate of amputation, calculated by 'the number of amputations per number of operated battle-injured limbs' was $16 \%$. 
Table 4. A mputation Characteristics.

\begin{tabular}{|l|l|l|}
\hline Level of Amputation & $\begin{array}{l}\text { Number of Limbs } \\
\text { (Casualty numbers) }\end{array}$ & Amputation Rates* (\%) \\
\hline Above elbow & $2(2)$ & \\
\hline Below elbow & $4(4)$ & 17 \\
\hline Above knee & $1(1)$ & \\
\hline Below knee & $7(6)$ & 15 \\
\hline TOTAL & $\mathbf{1 4 ( 1 3 )}$ & $\mathbf{1 6}$ \\
\hline
\end{tabular}

* Amputation Rate $=$ No. of amputations $/$ No. of battle-injured extremity operations

All but one of the amputations was performed at initial presentation. The sole delayed amputation (below knee amputation) was performed because of subsequent ischaemia of that limb. All amputated limbs sustained injuries consistent with Gustilo-Anderson (4) Grade 3. There were two unsuccessful attempts at limb salvage for vascular injuries, in two separate limbs, using vein grafts. Seven external fixators were used in the femur $(n=3)$, tibia $(n=2)$, radius $(n=1)$ and pelvis $(n=1)$. N one of the amputations were performed for sepsis.

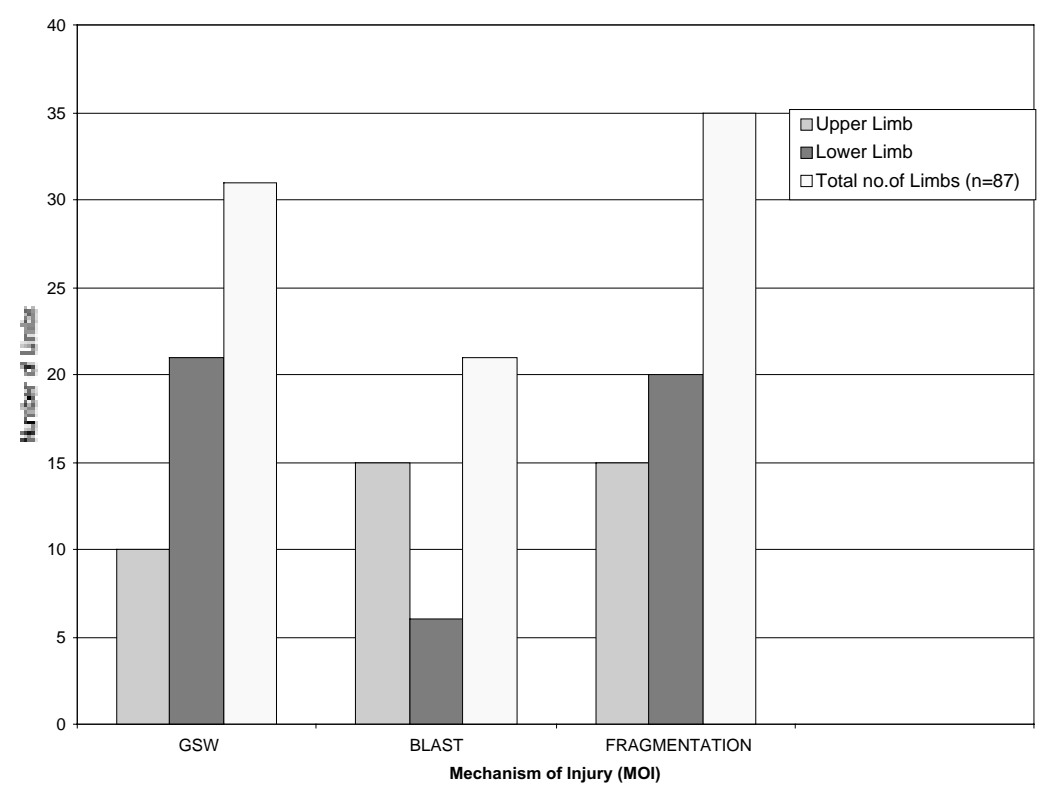

Fig 2. Distribution of Battle-injured Limbs according to the M echanism of Injury (MOI).

\section{Discussion}

Unlike recent conflicts in Afghanistan and Gulf War I, which involved a prolonged air bombardment campaign, 'G ulf War II' was fought in a more conventional manner using heavy artillery and handheld firearms. 34 Field Hospital, a 200 bed British Field Hospital, was located approximately 5 kilometres from the front line, a situation last seen in World War I (5). C onsequently, it was able to receive casualties directly from the front line, often bypassing first and second line combat medics and surgical teams, who would otherwise provide initial medical support at or near the front line. During the conflict period the hospital also treated enemy prisoners of war and Iraqi civilians.
Our findings that $83 \%(68 / 82)$ of battle casualties undergoing surgery sustained injury to the extremity compares well with the $70 \%$ and $92 \%$ figures quoted by Coupland (1) and Bhatnagar et al (6) for patients treated for war wounds to extremities. During the conflict period, surgery for battle-injured extremities represented more than half of all surgical procedures performed (53\%) and comprised of $58 \%$ of all operating theatre episodes.

It would seem that despite the close proximity of 34 Field H ospital to the front line, the relatively high surgical workload conferred by extremity-injured casualties is maintained.

In their paper, $\mathrm{H}$ eidarpour and colleagues describe laparotomy as the overall commonest surgical intervention in ten field hospitals during the I ran-I raq war (3). The medical facilities in their paper were described as field hospitals (and not forward surgical units) and were situated near the front line. The implication is that the large number of injuries to the abdomen dealt with there was a consequence of the type of war-fighting or weapons used. Alternatively, it maybe that only life saving procedures were performed at these ten field hospitals, with the less urgent extremity injuries being dealt with at medical facilities further back from the front line.

The proportion of laparotomies at 34 Field $\mathrm{H}$ ospital, which was also situated near the front line, was $17 \%(n=14)$ compared with the $30 \%$ reported by $\mathrm{H}$ eidarpour and colleagues.

The experience at the Vinkovci General Hospital, which was situated " 400 metres from the front line", during the war in Croatia, seems to mirror our high surgical workload in treating extremity-injured casualties (7). Sixty percent of all surgical procedures were for injured extremities with $90 \%$ of all casualties sustaining fragmentation wounds.

The distribution of battle-injured limbs according to the M OI (Figure 2) at 34 Field Hospital appears to differ from that observed in recent conflicts. Our finding that GSW accounted for 35\% of operated limb injuries compares with that from recent conflicts in Somalia (59\%) and Grenada (72\%) (8). The higher figures given by Islinger and colleagues may be explained by the fact that their data concentrated only on U.S troops rather than including enemy prisoners and civilians that were injured during these smaller scale conflicts.

The fewer blast/mines related injuries seen, particularly to the lower limbs, could be due to two possibilities. Firstly, that fewer antipersonnel mines or cluster bombs were deployed during this conflict and 
second, the low 'exposure' of personnel to these weapons during the conflict period (civilian population movements were curbed by curfews and, as is evident now, the majority of Iraqi forces did not engage in combat).

The overall predominant $\mathrm{MOI}$, due to fragmentation injuries, is the same as described by others authors (7-9).

In total 14 major amputations (Table 3) were performed in 87 battle-injured extremities that underwent surgery. Our amputation rate of $16 \%$ compares well with those described from the recent conflicts in Somalia (14\%), Grenada (19\%) and Iraq, during Gulf War I (14\%) (10).

Whether or not surgical facilities are located near a conflict zone, surgery to battleinjured extremities is not only common but also comprises the majority of the workload of the surgical team in a field hospital. The experience of 34 Field $\mathrm{H}$ ospital in the recent conflict in Iraq confirms this. Surgical resources should, therefore, be concentrated on the management of these injuries and surgical teams should be well versed in the management of casualties with limb trauma.

\section{References}

1. Coupland RM. War wounds of bones and external fixation. Injury 1994; 25(4):211-17.

2. Rautio J, Paavolainen P. Afghan was wounded: experience with 200 cases. J Trauma 1988; 28(4): 523-5.

3. Heidarpour A, Jahani M R, Dabbagh A, K hatami $M S$. Surgical interventions at field hospitals during the I ran and I raq War (1980-1987). M il M ed 1999; 164(2):136-7.

4. Gustilo RB, Anderson J.T. Prevention of infection in the treatment of one thousand and twenty-five open fractures of long bones. Retrospective and prospective analysis. J B one Jt Surg 1976; 58A: $453-458$.

5. Crile GW. N otes on base hospital no. 4, U.S. army on active service. J AM A 1917; 206-7.

6. Bhatnagar M K, Smith GS. Trauma in the Afghan guerilla war: effects of lack of access to care. Surgery 1989; 105: 699-705.

7. Hodalic Z, Svagelj M, Sebalj I, Sebalj D. Surgical treatment of 1211 patients at theVinkovci G eneral hospital, Vinkovci, Croatia, during the 1991-1992 Serbian offensive in east Slavonia. M il M ed 1999; 164(11): 803-8.

8. Jovanic S, Wertheimer B, Zelic Z, G etos Z. Wartime amputations. M il M ed 1993; 158:755-66.

9. Korver AJ. Amputees in a hospital of the International Committee of the Red Cross. Injury 1993; 24 (9):607-9. 1927; 11:64-748.

10. Islinger RB, Kuklo TR, M CHale KA. A review of orthopaedic injuries in three recent U.S M ilitary Conflicts. M il M ed 1999; 165(6):463-5. 